\title{
Towards a City's Systems Integration Model for Smart City Development: A Conceptualization
}

\author{
Full paper - Submitted to CSCI-ISOT symposium \\ Vahid Javidroozi, Hanifa Shah, Adrian Cole, Ardavan Amini \\ Computing, Engineering, the Built Environment (CEBE) Faculty \\ Birmingham City University (BCU) \\ Birmingham, UK \\ \{Vahid.Javidroozi, Hanifa.Shah, Adrian.Cole, Ardavan.Amini\}@bcu.ac.uk
}

\begin{abstract}
Smart city development is a response to address the issues of urbanization and need for flexibility and agility in delivering services to citizens. City as a complex system of systems needs to be efficient, inter-operable, and integrated. Thus, similar to systems integration in enterprises, integration of city systems provides flexibility and access to real-time information for creation and delivery of efficient services. In addition, Business Process Change is essential for systems integration in smart city development. Similar to business process change in the private enterprises, there are a number of challenging dimensions in smart city development. This conceptualization research considers a city as a large-scale enterprise and attempts to design a business process centric model for city's systems integration.
\end{abstract}

Keywords-smart city; systems integration; business process change; smart city dimensions

\section{INTRODUCTION}

Today's fast growing urbanisation in the world is being one of the main concerns of the governments and authorities. Only 30 metropolises in the world have accommodated $10 \%$ of the global population. In the other figure, $25 \%$ of the world's population are living in 600 cities [1][2]. Therefore, those metropolises have to deliver high quality services to the large number of citizens. They should also interact with citizens immediately, efficiently, and effectively. For instance, they should provide immediate access to information, easy access to offices virtually rather than through physical offices with long queues, answer to citizens' questions, and resolve their problems [3]. In other respects, the cities' authorities should develop liveability for all citizens. Liveability and sustainability of the city are provided by making all components of a city smart. Developing smart city means all components, systems, subsystems, information, people, and business processes within the city should be smart, connected, and interoperable. Therefore, integration is a necessity for Smart City Development (SCD), and it has many dimensions and subdimensions that should be considered in all of its steps.

Since 1940s and 1950s, systems integration has become the most important and useful change within the enterprises to enhance their business performance and provide cheaper, quicker, and high quality services [4]. Systems integration in private enterprises has also a number of dimensions and drivers that have been / are being explained by researchers.
Business Process Change $\left(\mathrm{BPC}^{1}\right)$, which is also the most challenging aspect of systems integration, comprises some dimensions that should be precisely considered in systems integration.

The aim of this research is to conceptualize SCD in aspects of systems integration, BPC, and their dimensions.

The objectives are as follows

- $\quad$ Explore the literature regarding

- City's systems, $\mathrm{SCD}$, and its requirements

- Systems integration and its dimensions

- BPC and its dimensions and approaches

- Making relationship between SCD and systems integration in enterprises

- $\quad$ Designing a systems integration model for SCD

The next section of this research provides a literature review in the context of SCD and conceptualizes its necessities. Section III explains systems integration in enterprises and its dimensions. Then, BPC as a prerequisite for systems integration in both enterprises and SCD will be conceptualized. Finally, a model for city's systems integration will be given.

\section{SMART CITY}

\section{A. Necessity of Urban Innovation}

Currently, the fundamental human needs (physiological needs, safety, love, esteem, and self-actualisation [5]) have been advanced by factors such as globalisation, technology, and dramatic growth of urban population. Right to live in clean and green environment, to receive efficient and ontime health and social care, to economic growth, to be freely and conveniently mobile, to be easily informed, connected, and communicated are some examples of modern requirements, which are usually unseen or remained as unsolved challenges, especially in urban environments. These modern needs/rights cause current challenges for city authorities and the governments. For example, Birmingham City Council (UK) has categorised this challenges into seven

1

BPC is defined as analyze, redesign, and improve the existing business processes to achieve a competitive advantage in performance [36]. 
categories of economic, well-being, mobility, environmental, digital inclusion and skills, joined-up approach, and access to data [6].

As discussed by earlier researchers (such as [1][2][7][12]), rapid urbanization and deficiency of city services are the main issues for current and especially for the future cities. Rise of crime rate, waste management, traffic congestion, air pollution, massive energy demand, waste in energy consumption, and many more are the problems caused by rapid growth of urban population. These are all the challenges that the future cities will be faced, and smart city is a response to them [13].

Current improvements in individual city's operations and providing services achieved by technology innovations and engineering-based attempts are not enough to have a smart city. City should be seen as a system of systems, which interact, communicate, and share information with each other. The result of the collaboration through those systems is providing efficient, effective, and real-time services for the citizens. Therefore, their business processes are also changed from traditional and individual to cross-sectoral. Thus, for a sustainable living in the future cities, the cities should be run in a different way. In fact, the business processes within the cities should be modified and transformed [3][12][14][15].

\section{B. Smart City needs Smart Everything}

For developing a smart city, everything within the city including people, businesses, technology, processes, data, infrastructures, consumption, spaces, energy, strategies, management, and so forth should become smart. Considering everything is smart means these components should be connected, be supporting each other, use each other's data, and there is no waste. Thus, it is not only about implementing and using smart and innovative technologies. The technology should be a part of an integrated system, which creates smart city [16]. All pieces of technology in the city must also be integrated. In addition, we should create standards for smart cities [17]. Business processes are the other parts of this system that create the city services. They should be flexible, connected, dynamic, and agile [18].

For smart city, smart information and smart people are also required. Information should be easily useable, shareable, and connected. The role of IT in integration of systems and applications in various public sectors and governmental organizations has been highlighted. Local Government Authorities (LGAs) have implemented different IT systems for automation and improvement of their business processes and provide agile, flexible, and more efficient city services. Now, this role will be more prominent in systems integration across various sectors for providing a smart environment and facilitating more joined-up and citizens-centric services [19]. People should also interact with each other and with everything else like technologies, devices, and offices in an intelligent and smart manner. They should act as an integral part of economic, social, and cultural development of the city. They should also know how to use and interact with the smart facilities of their smart community [20]. Thus, for having a smart city all of these dimensions plus business processes should be changed and aligned with the integration process.

Moreover, integration is the most important necessity for developing a smart city, because it is a key task in nearly all areas of SCD. In addition, citizens do not need the information, which are locked within the silos of public sectors throughout the city. They need their requirements to be met by seamlessly connected services that are delivered by using all information and knowledge generated by the sectors and this is achieved by cross-sectoral city systems integration [19].

\section{SYSTEMS INTEGRATION}

Agreeing that integration of city systems is necessary for $\mathrm{SCD}$, it has to be clarified that what does systems integration mean. Integration has a particular meaning, which differs from the concepts such as inter-connection or intercommunication. The components of a system can be communicating with or linked to each other in order to perform the activities. This system called "intercommunicated" and "inter-connected", not necessarily "integrated". The departments/subsystems of the proposed system are connected to each other reciprocally, but without integration, they cannot be considered as a whole, because there is no seamless flow of information and processes between them [21][22].

Systems integration is a common term in private enterprises. It has been a crucial goal for enterprises since 1940 s, in order to improve their performance by sharing data, accessing real-time information, making decisions on time, and perform their business processes efficiently and effectively. Integration is a necessity to connect all business processes performed by different departments and organizations in order to exchange information amongst them. City as a system of systems is also considered as a large-scale enterprise, which includes all of its elements. Therefore, systems integration should be performed for SCD, similar to private sector in principle, but different and more complex in detail. Moreover, integration of technology with new business processes and organization builds an environment where employees can easily collaborate and communicate with each other and organizations' departments [23][24].

Overall, integration of enterprise systems itself is the main benefit and core capability for organizations, and that is all about access to real time information by all sections of an enterprise [4][25].

\section{A. Systems Integration Key Drivers}

Reference [23] has stated systems integration in four aspects of interconnectivity, interoperability, semantic consistency, and convergent integration. First, three of them are technology-oriented terms, but last one represents systems integration as a convergent of technology, people, process, and knowledge. Moreover, reference [26] believe that systems integration is a radical change in business. However, their research concentrates on people aspects. It is critical, in a successful systems integration, to improve all aspects of the business key drivers, which are processes, 
people, and technology as well as flow of information amongst them. These are introduced as systems integration key drivers. In addition, the definition of "system" itself includes these key drivers and they defined system as a collection of entities including process, people, and technology [27]. Moreover, reference [28] called them subsystems of an organisational system. Thus, for integrating enterprise systems these triangle elements should not be considered separately and they have to be integrated. "People" are implementers of BPC, and "technology" is an enabler to perform business processes as quick and easy as possible. Technology allows people to manage [29]. Flow of data and information through all of these elements is also necessary especially when technology is inserted for BPC [30]. Consequently, enterprises need to have eager and prepared people, along with appropriate technology as an enabler for a successful Systems Integration. They also have to change their business processes. Thus, BPC is main area of activities in systems integration, because integration of business processes addresses some issues in other areas of systems integration. Thus, enterprises should shift from functional-oriented integration to process-oriented integration [31][32]. In addition, reference [33] identified three main challenging areas that need to be considered by organization's managers for a successful systems integration.

\section{BPC}

According to Mintzburg's organizational structure [34], Contingency theory [35], and as concluded by reference [33], for a successful systems integration, the organizational structure should fit to ES integrator (such as ERP). In order to achieve this goal, a number of changing in business processes is required. Business process change/redesign is necessary to change, improve, and integrate existing business processes, using some approaches, tools, and techniques such as BPMo, BPR, TQM, and Six Sigma [36][37].

BPC is a complex project, which is affected by enterprise's capabilities such as change management, project management, and IT, and needs to be managed and planned carefully [37]. It is a complex task for improving business processes and organisation performance [38]. Reference [39] considered the role of technology and people in BPC for systems integration. They have defined BPC as a strategydriven improvement and re-design of business processes through management, IT, organizational structure, and people in order to achieve competitive advantage in performance. The enhancement of business process performance in terms of quality, adaptability, value, sensitivity, and customer contentment are some meaningful advantages of BPC [26].

Sometimes Business Process Reengineering (BPR) is explained as same meaning as BPC. Reference [39] have also discussed about the confusion regarding the terms BPR and BPC. Contradictory, they have synonymised BPC and BPR and have utilised BPR steps for BPC stages, by considering $\mathrm{BPC}$ and Business Process Improvement (BPI) synonymous and theorising that "both BPC and BPR are included in business process redesign definition" [39]. In contrast, reference [40] explained that both BPR and BPI are included in business process redesign. In addition, according to definition of BPC by reference [39], as well as described by reference [41], BPC is equal to redesigning business processes. As a result, BPR and BPI are included in BPC. Moreover, reference [39] have introduced BPR as a radical change and BPC as an incremental approach. However, as defined by many researchers, BPR is an approach/technique for $\mathrm{BPC}$, in order to improve business performance dramatically [37][41][42]. Therefore, BPR is a sub-category for BPC, which can be done in two different approaches/modes: revolutionary/radical (e.g. BPR) or evolutionary (e.g. TQM) [40] (Figure 1). In other words, $\mathrm{BPC}$ comprises many tools and techniques, which pursue one of the evolutionary or revolutionary approaches. Hence, enterprises (including large scale enterprise of city) have to learn how to do both [43].

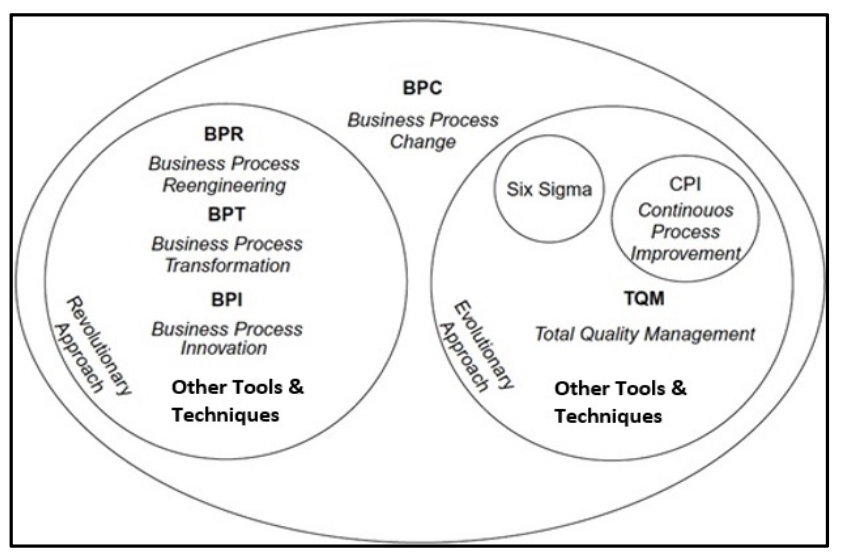

Fig. 1. BPC approaches (adapted from [37])

\section{A. BPC dimensions}

The enterprises and cities are threatened by many challenges, risks, and dimensions to go through a comprehensive BPC for systems integration. Therefore, paying attention to all dimensions of BPC especially for cities is essential. Practically, all BPC tools, techniques, and approaches have also been developed to facilitate the procedure and address the challenges of BPC. In addition, the success level of BPC depends on their capabilities to address those challenges and dimensions [37]. Thus, cognition of those challenging dimensions is crucial before performing any change in business processes.

Reference [38] believed that BPC includes many challenges such as inter-dependencies between processes, departments, stakeholders, their attributes, and applications. These are just some challenges that enterprises and cities are involved during changing the business processes, but there are many challenges in two other dimensions, which are people and technology. In fact, the challenges of systems integration can be categorized according to systems integration key drivers. Thus, the dimensions of systems integration for SCD will be human related, BPC related, and technological. Nevertheless, again the BPC challenges are involved with "People" and "Technology" aspects (Figure 6). For instance, "ability of employees to learn", "cultural readiness", and "interpersonal relationship" are imperative 
factors in BPC, which are directly related to People. Moreover, "IT influence in BPC" [37] is "Technology" related challenges that need to be tackled by choosing the most appropriate systems integrator. Reference [44] has declared them as BPC challenges, because they are the issues that need to be considered during transforming the processes.

According to Kettinger and Grover's BPC model [45] (figure 2), in addition to functional and inter-organizational aspects, there are four dimensions of people, information \& technology, management, and structure for BPC. Nevertheless, the factors, which have been represented in structure category, can be classified in other categories such as management, because they are parts of management tasks. Thus, this research combines structure and management dimensions into a single managerial category.

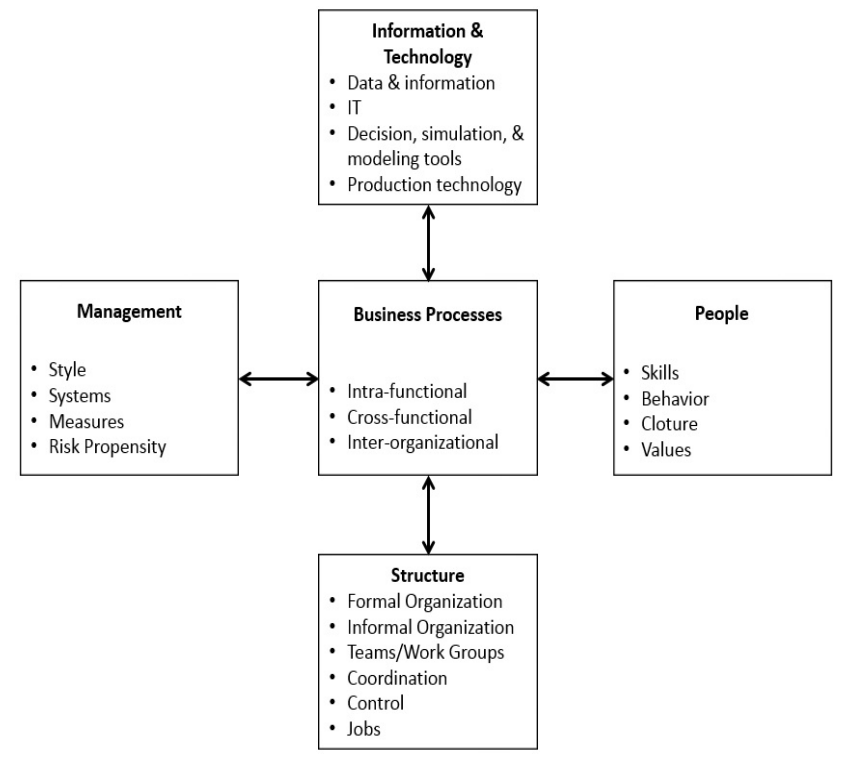

Fig. 2. BPC model (adopted from [45])

In addition, this study categorises BPC dimensions into three main categories of technology related, human issues, and purely process related dimensions. Furthermore, purely process related dimension would also be classified into three more dimensions of managerial (including Kettinger and Grover's structure category), inter-organizational, and functional challenges (figure 3 ).

In each dimension, there are many challenges that smart city developers would face with them. For instance, in managerial dimension they should deal with challenges such as governance, control, inter-dependencies, and interoperation between city's systems. In functional dimension, smart city developers should enhance agility and flexibility, and reduce complexity of systems integration and business processes. In inter-organizational dimension they should address the challenges like autonomy, confidentiality, and business process ownership [29][38][39][46]-[61].

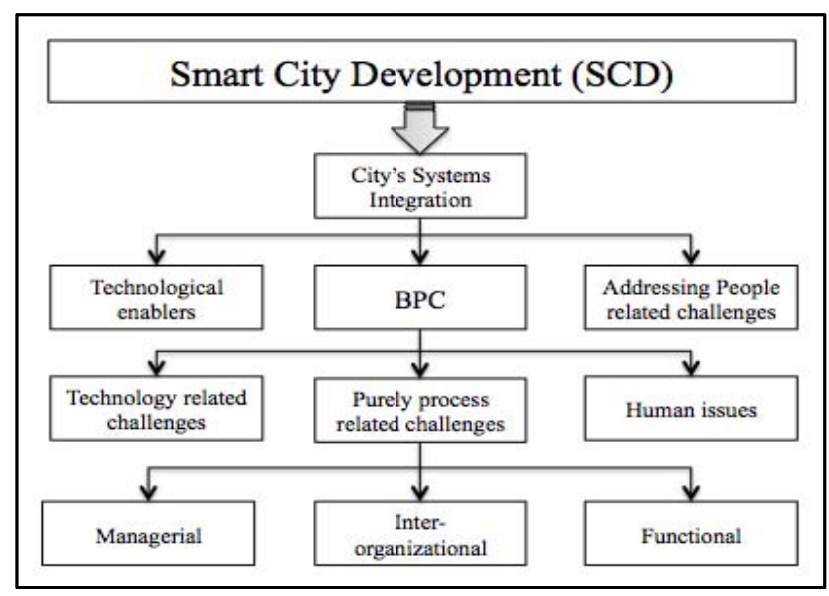

Fig. 3. City's Systems Integration Model

\section{CONCLUSION}

Fast growing urbanisation in the world necessitated developing smart cities. This research considered city as a large-scale and complex enterprise and conceptualized that integrating city's systems is essential for smart cities, in order to provide efficient, real-time, and effective services for the citizens, and providing inter-communication and inter-operation between sectors and their systems. In addition, the proposed research provided a model and demonstrated that systems integration has three main dimensions of technology, people, and BPC. Moreover, BPC has five main dimensions of technology related, human issues, managerial, inter-organizational, and functional.

\section{References}

[1] T. Nam and T. A. Pardo, "Smart city as urban innovation," in Proceedings of the 5th International Conference on Theory and Practice of Electronic Governance - ICEGOV'11, 2011, p. 185.

[2] H. Chourabi, T. Nam, S. Walker, J. R. Gil-Garcia, S. Mellouli, K. Nahon, T. A. Pardo, and H. J. Scholl, "Understanding Smart Cities: An Integrative Framework," in 2012 45th Hawaii International Conference on System Sciences, 2012, pp. 22892297.

[3] C. Harrison and I. A. Donnelly, "A Theory of Smart Cities," in Proceedings of the 55th Annual Meeting of the ISSS - 2011, Hull, UK, 2011, vol. 55, no. 1.

[4] M. Hobday, "Systems integration: a core capability of the modern corporation," Ind. Corp. Chang., vol. 14, no. 6, pp. 1109-1143, Aug. 2005.

[5] A. H. Maslow, "A theory of human motivation.," Psychol. Rev., vol. 50, no. 4, pp. 370-396, 1943.

[6] Birmingham City Council, "Birmingham Smart City," Birmingham, 2012.

[7] R. Alsnih and D. A. Hensher, "The mobility and accessibility expectations of seniors in an aging population," Transp. Res. Part A Policy Pract., vol. 37, no. 10, pp. 903-916, Dec. 2003.

[8] T. Nam and T. A. Pardo, "Conceptualizing smart 
city with dimensions of technology, people, and institutions," in Proceedings of the 12th Annual International Digital Government Research Conference on Digital Government Innovation in Challenging Times - dg.o '11, 2011, p. 282.

[9] H. Schaffers, N. Komninos, and M. Pallot, "Smart Cities as Innovation Ecosystems Sustained by the Future Internet," 2012.

[10] A. Aldama-Nalda, H. Chourabi, T. A. Pardo, J. R. Gil-Garcia, S. Mellouli, H. J. Scholl, S. Alawadhi, T. Nam, and S. Walker, "Smart cities and service integration initiatives in North American cities: Astatus report," in Proceedings of the 13th Annual International Conference on Digital Government Research - dg.o '12, 2012, p. 289.

[11] S. AlAwadhi and H. J. (Jochen) Scholl, "Aspirations and Realizations: The Smart City of Seattle," in 2013 46th Hawaii International Conference on System Sciences, 2013, pp. 1695-1703.

[12] P. Liu and Z. Peng, "Smart Cities in China," Computer (Long. Beach. Calif)., vol. PP, no. 99, pp. 1-1, 2013.

[13] BSI, "PAS 180 - Smart Cities Terminology | BSI Group," 2014.

[14] K. Marciniak and M. L. Owoc, "Usability of Knowledge Grid in Smart City Concepts," in 15th International Conference on Enterprise Information Systems, 2013, pp. 341-346.

[15] BSI, "PAS 181:2014 Smart city framework," 2014.

[16] Copenhagen Cleantech Cluster, "Danish Smart Cities: sustainable living in an urban world," Copenhagen.

[17] A. M. Townsend, Smart Cities: Big Data, Civic Hackers, and the Quest for a New Utopia. New York: W. W. Norton \& Company, 2013.

[18] A. Vojdani, "Smart Integration," IEEE Power Energy Mag., vol. 6, no. 6, pp. 71-79, 2008.

[19] M. M. Kamal, R. Hackney, and M. Ali, "Facilitating enterprise application integration adoption: An empirical analysis of UK local government authorities," Int. J. Inf. Manage., vol. 33, no. 1, pp. 61-75, 2013.

[20] S. Allwinkle and P. Cruickshank, "Creating Smarter Cities: An Overview," J. Urban Technol., vol. 18, no. 2, pp. 1-16, Aug. 2011.

[21] T. H. Davenport, "Putting the enterprise into the enterprise system," Harv. Bus. Rev., vol. 76, no. 4, pp. 121-131, Jul. 1998.

[22] T. H. Davenport, J. G. Harris, and S. Cantrell, "Enterprise systems and ongoing process change," Bus. Process Manag. J., vol. 10, no. 1, pp. 16-26, Jan. 2004

[23] J. M. Myerson, Enterprise Systems Integration, Second Edition (Best Practices). Auerbach Publications, 2001.

[24] D. M. R. Ferreira and J. J. P. Ferreira, "Towards a workflow-based integration architecture for business networking," Bus. Process Manag. J., vol. 11, no. 5, pp. 517-531, Jan. 2005.

[25] P. B. Seddon, C. Calvert, and S. Yang, "A multiproject model of key factors affecting organizational benefits from enterprise systems," MIS Q., vol. 34, no. 2, pp. 305-328, Jun. 2010.

[26] J. Motwani, D. Mirchandani, M. Madan, and A. Gunasekaran, "Successful implementation of ERP projects: Evidence from two case studies," Int. J. Prod. Econ., vol. 75, pp. 83 - 96, 2002

[27] C. E. Siemieniuch and M. A. Sinclair, "Systems integration.," Appl. Ergon., vol. 37, no. 1, pp. 91110, Jan. 2006.

[28] V. Grover, S. R. Jeong, W. J. Kettinger, and J. T. C. Teng, "The implementation of business process reengineering," J. Manag. Inf. Syst., vol. 12, no. 1, pp. 109-144, Jun. 1995.

[29] D. R. Shaw, C. P. Holland, P. Kawalek, B. Snowdon, and B. Warboys, "Elements of a business process management system: theory and practice," Bus. Process Manag. J., vol. 13, no. 1, pp. 91-107, Feb. 2007.

[30] N. Berente, B. Vandenbosch, and B. Aubert, "Information flows and business process integration," Bus. Process Manag. J., vol. 15, no. 1, pp. 119-141, Jun. 2009.

[31] C. V. Ramamoorthy, C. Chandra, H. G. Kim, Y. C. Shim, and V. Vij, "Systems integration: problems and approaches," in Proceedings of the Second International Conference on Systems Integration, 1992, pp. 522-529.

[32] H.-H. Hvolby and J. H. Trienekens, "Challenges in business systems integration," Comput. Ind., vol. 61, no. 9, pp. 808-812, Dec. 2010.

[33] N. A. Morton and Q. Hu, "Implications of the fit between organizational structure and ERP: A structural contingency theory perspective," Int. J. Inf. Manage, vol. 28, no. 5, pp. 391-402, Oct. 2008.

[34] H. Mintzberg, "The Structuring of Organizations: A Synthesis of the Research," Univ. Illinois UrbanaChampaign's Acad. Entrep. Leadersh. Hist. Res. Ref. Entrep., 1979.

[35] L. Donaldson, The Contingency Theory of Organizations. SAGE Publications, 2001.

[36] P. Harmon, Business Process Change: A Manager's Guide to Improving, Redesigning and Automating Processes. San Francisco: Morgan Kaufmann Publishers, 2003.

[37] M. C. Jurisch, W. Palka, P. Wolf, and H. Krcmar, "Which capabilities matter for successful business process change?," Bus. Process Manag. J., vol. 20, no. 1, pp. 47-67, Jan. 2014.

[38] A. Lodhi, V. Köppen, and G. Saake, "Business Process Improvement Framework and Representational Support," in Proceedings of the Third International Conference on Intelligent 
Human Computer Interaction, 2013, vol. 179, pp. 155-167.

[39] A. Pateli and S. Philippidou, "Applying Business Process Change (BPC) to Implement Multi-agency Collaboration: The Case of the Greek Public Administration," J. Theor. Appl. Electron. Commer. Res., vol. 6, no. 1, pp. 127-142, Apr. 2011.

[40] G. Valiris and M. Glykas, "Critical review of existing BPR methodologies: The need for a holistic approach," Bus. Process Manag. J., vol. 5, no. 1, pp. 65-86, Jan. 1999.

[41] P. Harmon and B. P. Trends, Business Process Change: A Guide for Business Managers and BPM and Six Sigma Professionals. Morgan Kaufmann, 2010.

[42] M. Hammer and J. Champy, Reengineering the corporation: a manifesto for business revolution. New York: Harper Business, 1993.

[43] T. H. Davenport, Process Innovation: Reengineering Work Through Information Technology. Massachusetts: Harvard Business Press, 1993.

[44] J. Motwani, "A business process change framework for examining lean manufacturing: a case study," Ind. Manag. Data Syst., vol. 103, no. 5, pp. 339346, Jan. 2003.

[45] W. J. Kettinger and V. Grover, "Toward a theory of business process change management - ProQuest," J. Manag. Inf. Syst., vol. 12, no. 1, p. 9, 1995.

[46] J. Lee, K. Siau, and S. Hong, "Enterprise integration with ERP and EAI," Commun. ACM, vol. 46, no. 2, pp. 54-60, Feb. 2003.

[47] M. H. Larsen and R. Klischewski, "Process ownership challenges in IT-enabled transformation of interorganizational business processes," in 37th Annual Hawaii International Conference on System Sciences, 2004. Proceedings of the, 2004, p. 11 pp.

[48] O. Volkoff, D. M. Strong, and M. B. Elmes, "Understanding enterprise systems-enabled integration," Eur. J. Inf. Syst., vol. 14, no. 2, pp. 110-120, Jun. 2005.

[49] W. Bandara, M. Indulska, S. Chong, and S. Sadiq, "Major Issues in Business Process Management: An Expert Perspective," in ECIS 2007 - The 15th European Conference on Information Systems, 2007, pp. 1240-1251.

[50] C. Legner and K. Wende, "“The Challenges of Interorganizational Business Process Design - a Res' by Christine Legner, et al.," in European Conference on Information Systems (ECIS 2007), 2007, pp. 1643-1654.

[51] D. Chen, G. Doumeingts, and F. Vernadat, "Architectures for enterprise integration and interoperability: Past, present and future," Comput. Ind., vol. 59, no. 7, pp. 647-659, 2008.

[52] C. Liu, Q. Li, and X. Zhao, "Challenges and opportunities in collaborative business process management: Overview of recent advances and introduction to the special issue," Inf. Syst. Front., vol. 11, no. 3, pp. 201-209, May 2008.

[53] P. Trkman, "The critical success factors of business process management," Int. J. Inf. Manage., vol. 30, no. 2, pp. 125-134, Apr. 2010.

[54] M. L. Markus and D. D. Jacobson, "Business Process Governance," in Handbook on Business Process Management 2, J. vom Brocke and M. Rosemann, Eds. Berlin, Heidelberg: Springer Berlin Heidelberg, 2010, pp. 201-222.

[55] A. Momoh, R. Roy, and E. Shehab, "Challenges in enterprise resource planning implementation: stateof-the-art," Bus. Process Manag. J., vol. 16, no. 4, pp. 537-565, Jul. 2010.

[56] H. A. . Awad and M. O. Nassar, "Supply Chain Integration: Definition and Challenges," in Proceedings of the International MultiConference of Engineers and Computer Scientists, 2010.

[57] L. Da Xu, "Enterprise Systems: State-of-the-Art and Future Trends," IEEE Trans. Ind. Informatics, vol. 7, no. 4, pp. 630-640, Nov. 2011.

[58] D. D. Vaziri and D. DeOliveira, "Accessible Business Process Modelling," Int. J. Soc. Hum. Sci., vol. 6, pp. 205-216, 2012.

[59] M. Segatto, "Business process management: a systemic approach?," Bus. Process Manag. J., vol. 19, no. 4, pp. 698-714, Jul. 2013.

[60] R. Araujo, C. Cappelli, and P. Engiel, "Raising Citizen-Government Communication with Business Process Models," in Handbook of Research on Democratic Strategies and Citizen-Centered EGovernment Services, IGI Global, 2015.

[61] U. Kannengiesser, "Integrating CrossOrganisational Business Processes Based on a Combined S-BPM/DSM Approach," 2015. 